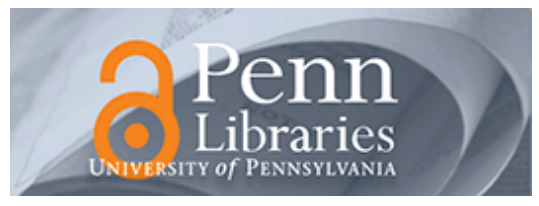

University of Pennsylvania ScholarlyCommons

8-1-2006

\title{
Balancing Exploration and Exploitation in Alliance Formation
}

Dovev Lavie

University of Pennsylvania

Lori Rosenkopf

University of Pennsylvania

Follow this and additional works at: https://repository.upenn.edu/mgmt_papers

Part of the Management Sciences and Quantitative Methods Commons

\section{Recommended Citation}

Lavie, D., \& Rosenkopf, L. (2006). Balancing Exploration and Exploitation in Alliance Formation. Academy of Management Journal, 49 (4), 797-818. http://dx.doi.org/10.5465/AMJ.2006.22083085

At the time of publication, author Dovev Lavie was affiliated with University of Texas. Currently, he is a faculty member at the Wharton School at the University of Pennsylvania.

This paper is posted at ScholarlyCommons. https://repository.upenn.edu/mgmt_papers/296

For more information, please contact repository@pobox.upenn.edu. 


\title{
Balancing Exploration and Exploitation in Alliance Formation
}

\begin{abstract}
Do firms balance exploration and exploitation in their alliance formation decisions and, if so, why and how? We argue that absorptive capacity and organizational inertia impose conflicting pressures for exploration and exploitation with respect to the value chain function of alliances, the attributes of partners, and partners' network positions. Although path dependencies reinforce either exploration or exploitation within each of these domains, we find that firms balance their tendencies to explore and exploit over time and across domains.
\end{abstract}

\section{Keywords}

Organizational structure, decision making, strategic alliances, research, absorptive capacity

Disciplines

Management Sciences and Quantitative Methods

\section{Comments}

At the time of publication, author Dovev Lavie was affiliated with University of Texas. Currently, he is a faculty member at the Wharton School at the University of Pennsylvania. 


\title{
BALANCING EXPLORATION AND EXPLOITATION IN ALLIANCE FORMATION: A MULTIDIMENSIONAL PERSPECTIVE
}

\author{
DOVEV LAVIE \\ McCombs School of Business \\ The University of Texas at Austin \\ 1 University Station, \\ Austin, TX 78712, USA \\ LORI ROSENKOPF \\ University of Pennsylvania \\ INTRODUCTION
}

We examine firm-level determinants of exploration and exploitation in alliance formation by contrasting an organizational inertia perspective with organizational slack and absorptive capacity perspectives. We classify alliances in the software industry as explorative versus exploitative along three dimensions: (a) the function that the alliance serves, (b) the structural network location of the partner, and (c) the partner's attributes. We find that firm age and partnering experience induce all three types of exploration. In contrast, the effect of financial success is contingent on the type of exploration studied: financial success drives function-based exploration while leading to attribute-based exploitation.

\section{THEORY AND HYPOTHESES}

\section{Three Dimensions of Exploration-Exploitation}

The Function-Based Dimension. Following Koza and Lewin (1998), alliances that engage partners in $R \& D$ that may lead to innovative technologies and applications have been typically categorized as exploration alliances, whereas alliances that focus on commercializing and utilizing existing technologies or employing complementary partner capabilities (Teece, 1986) have been typically categorized as exploitation alliances. In this sense, exploration alliances engage in upstream activities of the value chain, enabling partners to share tacit knowledge, create and learn new knowledge and capabilities. In contrast, exploitation alliances engage in downstream activities such as commercialization and marketing that leverage and combine partners' existing capabilities by exchanging explicit knowledge (Rothaermel, 2001b).

The Structure-Based Dimension. The structure-based dimension of explorationexploitation refers to the path length between the firm and partners positioned in its broadly defined network. In this sense, alliances formed with remote partners reflect exploration while those formed with proximate partners reflect exploitation. For example, Beckman, Haunschild, and Phillips (2004) argued that forming additional alliances with existing partners (i.e., a prior path length of 1) is a form of exploitation in which the firm reinforces its existing relationships in order to utilize and extend its current knowledge base. Generally, a short path length facilitates the flow of knowledge and information across partners and enhances the efficiency of their collaboration (Verspagen and Duysters, 2002). The case where a firm forms an alliance with a 
remote partner that lacked direct or indirect ties to the firm through any number of chained intermediaries can be classified as pure exploration, since the firm broadens its reach in attempt to access knowledge domains that cannot be channeled through its immediate network.

The Attribute-Based Dimension. The attribute-based dimension of explorationexploitation refers to the inter-temporal variance in the firm's pattern of alliance formation decisions. March (1991) associated exploration with experimentation and variation in organizational routines, processes, technologies, and applications. Specifically, exploration enhances adaptation to environmental changes by increasing variance (McGrath, 2001) and undertaking long jumps (Levinthal, 1997) that enable the firm to explore new knowledge outside its domain (Rosenkopf and Nerkar, 2001). Hence, a deviation from a systematic pattern of alliance formation with partners that share certain organizational attributes is considered an exploratory behavior. In contrast, when a firm forms new alliances with partners that are similar to prior partners in terms of their organizational attributes it can efficiently accumulate and apply its partnering experience and utilize efficient governance mechanisms in managing its alliances (Gulati, Lavie, and Singh, 2003; Hoang and Rothaermel, 2005). Such persistence in alliance formation patterns leads to repetition-based improvement, experiential learning and specialization, which are associated with exploitation (Levinthal and March, 1993).

\section{The Inertia Perspective on Exploration-Exploitation}

The organizational inertia perspective on exploration-exploitation in alliance formation builds on structural inertia theory (Hannan and Freeman, 1984). Organizational inertia is evident when the pace of reorganization is slower than the rate of environmental change. Such organizational persistence evolves as a result of internal factors such as irreversible investments, managerial commitment, and employee resistance, as well as external factors such as entry and exit barriers, constraints on information accessibility, and institutional legitimation (Hannan and Freeman, 1984, 1989). These social pressures favor rational strategies designed to enhance productivity and lead to reproducible, reliable and accountable outcomes. In this sense, the organizational inertia perspective emphasizes exploitation and experiential learning (Levinthal and March, 1993; Levitt and March, 1988; March, 1991).

The Implications of Firm Age. The inertia perspective suggests that as firms mature, they are less likely to engage in exploration. Older firms develop managerial commitment to existing technologies (Burgelman, 1994; Kelly and Amburgey, 1991), and are less likely to explore new technologies through their alliances. In support of this argument, Rothaermel (2001b) found that incumbents benefited by exploiting complementary assets rather than by exploring new technologies with partners. In addition, firms nurture relationships as they mature and become embedded in alliance networks. This embeddedness encourages repeated alliances with prior partners (Gulati, 1995b; Li and Rowley, 2002), which are instituted on familiarity, trust, and established collaboration routines. Finally, maturation leads to the development of organizational routines that become embedded in decision-making processes and are applied almost automatically in response to external stimuli (Nelson and Winter, 1982). When a new problem arises, firms engage in local search for relevant experiences (Cyert and March, 1963) and elicit a response that conforms to their established routines. Therefore: 
H1a: Exploration in alliance formation decreases with firm age.

The Implications of Partnering Experience. Firms that have accumulated partnering experience are expected to develop corresponding routines that foster exploitation, thus reducing exploration in alliance formation. As a firm's alliance network evolves and partnering experience is accumulated, organizational routines evolve to enable the firm to pursue alliances more efficiently, thus favoring marketing alliances to R\&D alliances that entail substantial interaction, collaboration, and exchange of tacit knowledge (Rowley, Behrens, and Krackhardt, 2000). Extensive partnering experience may also lead to alliance formation routines that promote local search driven by efficiency and partner accessibility. The frequency of employing a routine increases its efficient use and the likelihood of desirable outcomes, which in turn reinforce its application (Levinthal and March, 1993; Levitt and March, 1988), allowing the firm to accumulate and apply its partnering experience without encountering significant adjustment costs (Gulati et al., 2003; Gulati and Singh, 1998). Moreover, firms with extensive partnering experience are likely to find prior or structurally proximate partners to satisfy emerging needs.

H2a: Exploration in alliance formation decreases with accumulated partnering experience.

The Implications of Financial Success. Experiential learning involves trial-and-error sequences that lead to the evolution of routines (Nelson and Winter, 1982). Financial success reinforces established routines and restrains the employment of alternative routines that may emerge in new learning situations. In contrast, under conditions of financial failure, firms tend to seek new routines and frequently change their established routines (Levitt and March, 1988). In this regard, Levinthal and March (1993) identified failure and success traps, noting that failure encourages search and exploration, which increases the likelihood of future failure and further reinforces exploration. In contrast, financial success drives out exploration. Since financial returns on exploitation are relatively immediate and certain compared to those accruing from exploration (March, 1991), exploration tends to be discounted when the firm is financially stable. In sum, financial success motivates exploitation at the expense of exploration.

H3a: Exploration in alliance formation decreases with financial success.

\section{The Slack and Absorptive Capacity Perspectives on Exploration-Exploitation}

The organizational slack and absorptive capacity perspectives offer contrasting predictions to those drawn from the organizational inertia perspective. Organizational slack refers to the accumulated spare resources and surplus funds that can be discretionally used for adaptation or for buffering a firm from environmental demands since they are not already assigned to any requisite expenditure. Firms are more inclined to experiment with new strategies and support risky innovations in response to environmental demands when organizational slack is abundantly available to support such activities (Cyert and March, 1963; Mohr, 1969; Carter, 1971). Thus, risk-taking behavior becomes acceptable to the extent that organizational slack can shield the firm from the consequences of failed exploration (Singh, 1986).

The Implications of Financial Success. Organizational slack is often derived from prior financial success and has been thus operationalized with financial ratios such as profitability and 
solvency (Bourgeois, 1981; Bromiley, 1991; Cheng and Kesner, 1997; Greve, 2003). Because alliances may be more efficient than the internal organization in carrying out risky and innovative activities, the intensity of exploration in alliance formation is expected to be at least as high as exploration via the firm's internal units. Therefore, when financial resources are abundantly available, firms will experiment and invest more in the exploratory activities of their alliances. In contrast, when firms are short in financial resources, they will be inclined to restrict non-core activities, which in most cases are carried out through alliances rather than through the firm's internal organization. Hence, financial success may induce investments in external alliances and foster exploration in alliance formation.

H3b: Exploration in alliance formation increases with financial success.

The Implications of Firm Age and Partnering Experience. The organizational slack argument makes the implicit assumption that a firm with abundant slack resources can identify the need for and direction of exploratory activities to which these resources are then assigned. While the traditional slack literature elaborated on the contribution of organizational slack to innovation and performance, less attention was devoted to the processes of slack accumulation and utilization. A firm's accumulated experience is essential for developing absorptive capacity, which in turn explains slack-induced exploration in alliance formation.

Exploration derives from the firm's own experience, through processes of learning-bydoing (Levitt and March, 1988). However, due to time-compression diseconomies (Dierickx and Cool, 1989), the accumulated experience can be useful in exploration only to the extent that sufficient time elapsed to allow for its recording, processing, conservation, retrieval, and interpretation (Argote and Ophir, 2002; Levitt and March, 1988; Zollo and Winter, 1999). The firm's accumulated absorptive capacity, which derives in part from its intra-organizational experience, increases the likelihood that the firm will identify opportunities outside its technological domain, thus encouraging function-based exploration in the form of $R \& D$ alliances. In addition, the broad knowledge base of an experienced firm can be extended only to the extent that it forms alliances with partners that offer new external knowledge, otherwise the firm could have explored these opportunities through internal development. Consequently, alliances are likely to be formed with structurally remote and distinctive partners. In sum, intrafirm experience, which accumulates with firm age, enhances exploration.

H1b: Exploration in alliance formation increases with firm age.

Exploration derives not only from the firm's own experience, but also from its experience with alliance partners (Grant and Baden-Fuller, 1995; Koza and Lewin, 1998; Lane, Salk, and Lyles, 2001; Scott, 2003). Firms develop partner-specific absorptive capacity and engage in organizational learning by interacting with partners and accumulating joint experiences with these partners (Lane and Lubatkin, 1998). Indeed, prior research has demonstrated how a firm's network position affects its capacity to innovate (Ahuja, 2000; Tsai, 2001) and how prior alliance relationships contribute to absorption of partners' capabilities (Mowery, Oxley, and Silverman, 1996). In this study, we suggest that a firm's partnering experience may enhance exploration in alliance formation. As in the case of firm age, inter-organizational experience contributes to the firm's accumulated absorptive capacity, which enables the firm to engage in exploration. Thus: 
H2b: Exploration in alliance formation increases with accumulated partnering experience.

\section{METHODS}

We tested our hypotheses with a sample of 367 focal firms in the U.S. software industry (SICs 7371 through 7374). The study's timeframe spanned the years 1990 to 2001, yet historical alliances were tracked back to 1985 in order to analyze patterns of alliance formation behavior. Records of alliances were compiled through exhaustive searches in the SDC, Factiva, and Edgar databases. In total, 20,779 alliances were identified, involving 8,801 unique partners. In order to obtain partner-specific data, partners were traced in the Compustat database. The 2,884 identified publicly-traded partners in the sample accounted for $66 \%$ of the alliances. Firm- and partnerspecific data, such as historical SIC code, total assets, revenues, long-term debt, R\&D expenses and net income, were extracted on an annual basis from the Compustat database.

Our analyses were performed at the firm-year level of analysis. Thus, the alliance data were transformed to 2,623 firm-year observations by pooling the data for all alliances formed by each focal firm in a given year. In order to calculate meaningful measures, 436 records corresponding to firm-years with insufficient partnering history (less then two prior alliances) were eliminated. Due to missing values and variable computation restrictions, the effective sample size used in multivariate analysis ranged from 807 to 1634 observations.

The three types of exploration were operationalized as follows. For function-based exploration, we distinguished whether the alliance involved a knowledge-generating R\&D agreement, another type of agreement based on existing knowledge involving joint marketing and service, OEM/VAR, licensing, production, or supply, or a combination of R\&D and other agreements. For structure-based exploration, we determined the prior path length between the firm and each alliance partner. For attribute-based exploration, we calculated the deviation of the current partner's attribute value from the average attribute value of the firm's prior 10 alliance partners in respect to organizational size, marketing expenses, financial strength, and industry classification. Since many firms form multiple alliances in a given year, for all types of exploration, we averaged these tendencies across all alliances formed in the given firm-year.

Our independent variables were lagged by one year. For each firm, we collected yearly age, profitability (ROA) and solvency (cash/long-term debt) measures. In addition, we measured firm partnering experience by the accumulated number of all prior alliances formed by the focal firm with any partner between the year 1985 and the preceding year. We also controlled for year effects, firm size (assets), R\&D intensity, and prior ties of the focal firm. The analysis was conducted using cross-section time-series regressions with random effects models and generalized-least-square (GLS) estimators with first-order autoregressive errors.

\section{RESULTS}

Our results (tables available from the authors) suggest that the three dimensions of exploration-exploitation are largely uncorrelated, highlighting the importance of incorporating different measures of exploration-exploitation. With regard to our hypotheses, firm age produced positive effects on structure- and attribute-based exploration. Specifically, older firms formed more alliances with partners that were structurally distant and differed in size and financial strength. In addition, prior partnering experience produced significant positive effects on function-based exploration and some aspects of attribute-based exploration (specifically, 
partner marketing), thus offering support to the absorptive capacity perspective (H1b and H2b).

In contrast, the effect of prior financial success, when measured by firm profitability, was contingent on the type of exploration analyzed. Specifically, profitability produced a positive effect on function-based exploration, but its impact on attribute-based exploration was consistently negative in respect to marketing, financial strength, and industry focus of partners. Hence, the inertia perspective (H3a) gained support in respect to attribute-based exploration while the slack perspective (H3b) gained support in respect to function-based exploration.

\section{DISCUSSION}

Our multidimensional perspective on exploration and exploitation in alliance formation demonstrates how exploration can be observed in the domains of alliance content (functionbased), partner identity (structure-based), and partner profile (attribute-based). Thus, any discussion of balancing exploration and exploitation need not be confined to one of these domains. Rather, firms can balance these activities across distinctive domains.

Considering simultaneous exploration and exploration with respect to the function-, structure-, and attribute-based dimensions also allows us to reconcile the competing predictions about the drivers of exploration and exploitation as revealed by the inertia, slack and absorptive capacity perspectives. Specifically, our findings concerning the implications of financial success demonstrated contingent effects of the competing inertia and slack mechanisms on exploration across the multiple dimensions. Whereas the organizational slack perspective explains the positive effect of financial success on function-based exploration, the organizational inertia perspective accounts for its contribution to attribute-based exploitation. Stated differently, excess returns and available cash flows encourage firms to pursue riskier projects by forming more $\mathrm{R} \& \mathrm{D}$ alliances with partners, yet at the same time, they encourage firms to form alliances with similar partners that resemble their prior partners in terms of organizational attributes and industry focus. In this sense, exploration and exploitation are balanced across different dimensions, allowing the firm to innovate and experiment with emerging technologies while benefiting from the efficiency of managing and governing alliances with similar partners.

With respect to firm age and partnering experience, our results clearly supported the slack and absorptive capacity perspectives with no contingencies across dimensions of exploration. Older firms with substantial partnering experience tended to engage in exploration rather than exploitation in alliance formation. Hence, a firm's accumulated experience is essential for expanding its knowledge domain and pursuing emerging opportunities that contribute to innovation and variation through alliance formation. While experience may also lead to the evolution of rigid routines and inertial forces, we found no evidence that such processes enforce exploitation. It is possible, however, that inertial forces reduce the efficiency of exploration without constraining the tendency to explore, at least in the context of alliances. While our findings are consistent with prior research showing increase in the rate of innovation with firm age (Sorensen and Stuart, 2000), they stand in contrast with the inertia literature that argued for limited responsiveness of older firms to organizational change (Amburgey, Kelly, and Barnett, 1993; Hannan and Freeman, 1984; Kelly and Amburgey, 1991). Possibly, older firms that encounter inertial impediments for innovation explore through alliances while pursuing exploitation through their internal units.

\section{REFERENCES AVAILABLE FROM THE AUTHORS}


Copyright of Academy of Management Proceedings is the property of Academy of Management. The copyright in an individual article may be maintained by the author in certain cases. Content may not be copied or emailed to multiple sites or posted to a listserv without the copyright holder's express written permission. However, users may print, download, or email articles for individual use. 